\title{
BMJ Open Diet and Exercise for FRAILty (DEFRAIL): protocol for a study to examine the effect of a novel community-based group exercise and nutritional intervention, designed to reverse frailty in older adults
}

\author{
Pádraig Bambrick (1) , ${ }^{1,2}$ Niamh Phelan, ${ }^{1}$ Emma Grant, ${ }^{1}$ Thomas Byrne,${ }^{3}$ \\ Michael Harrison, ${ }^{3}$ Ríona Mulcahy, ${ }^{1,2}$ John Cooke ${ }^{1,2}$
}

To cite: Bambrick P, Phelan N, Grant $\mathrm{E}$, et al. Diet and Exercise for FRAllty (DEFRAIL): protocol for a study to examine the effect of a novel community-based group exercise and nutritional intervention, designed to reverse frailty in older adults. BMJ Open 2021;11:e042408. doi:10.1136/ bmjopen-2020-042408

- Prepublication history and supplemental material for this paper is available online. To view these files, please visit the journal online (http://dx.doi org/10.1136/bmjopen-2020042408).

Received 27 July 2020 Revised 02 December 2020 Accepted 03 February 2021

Check for updates

(c) Author(s) (or their employer(s)) 2021. Re-use permitted under CC BY-NC. No commercial re-use. See rights and permissions. Published by BMJ.

${ }^{1}$ Department of Geriatric Medicine, University Hospital Waterford, Waterford, Ireland ${ }^{2}$ Department of Medicine, Royal College of Surgeons in Ireland, Dublin, Ireland

${ }^{3}$ Department of Sport \& Exercise Science, Waterford Institute of Technology, Waterford, Ireland

Correspondence to Dr Pádraig Bambrick; pbambrick@gmail.com

\section{ABSTRACT}

Introduction Frailty refers to a multifaceted age-related loss of physiological reserve. Aside from the immediate challenges it presents, it is also associated with various adverse health outcomes. Given our ageing population, the healthcare and societal costs resulting from frailty present a significant and growing public health challenge. Rapidly accumulating evidence suggests that resistance exercise combined with protein supplementation can reverse frailty in older adults. However, translation of these findings into practice has proven difficult, due to either a lack of clarity regarding the interventions used or the use of interventions not suitable for widespread implementation. There remains an absence of evidence-based programmes suitable for delivery to frail older adults in the community.

Methods and analysis This paper outlines the protocol for a study to examine the effect of a novel programme of exercise and protein supplementation. This intervention has been developed by an expert consensus group, specifically for delivery to frail older adults in a group setting in the community. The study will take the form of a within-subjects non-randomised trial. Participants will be assessed at baseline, then following an 8-week period of regular activity, then following the 8-week intervention. Frailty (according to the Fried Frailty criteria) will be the primary outcome measure, along with a range of secondary outcome measures (including physical performance measures, body mass composition, psychosocial assessments and frailtyrelated biomarkers). If shown to be feasible to implement and effective at reversing frailty, the Diet and Exercise for FRAILty (DEFRAIL) intervention may facilitate more widespread participation in resistance exercise for frail older adults.

Ethics and dissemination This study received ethical approval from the Research Ethics committees of both the Health Service Executive South-Eastern Area and Waterford Institute of Technology. Its findings will be disseminated through journal publications, conference presentations and other forms of public engagement. Trial registration number ISRCTN46458028; Pre-results.
Strengths and limitations of this study

- Novel exercise and protein intervention, specifically designed for frail older adults by expert consensus, with a focus on suitability for real-world implementation.

- Inclusive eligibility criteria.

- Comprehensive assessment of frailty and associated measures.

- Single-site study.

Non-randomised study design.

\section{INTRODUCTION}

Frailty refers to a loss of physiological reserve and increased vulnerability to external stressors. ${ }^{1}$ It is known to be associated with ageing but is not an inevitable consequence of the ageing process. In addition to conferring increased mortality risk on older adults, ${ }^{2}$ frailty is accompanied by a range of adverse health outcomes, including falls, fractures and functional impairment. ${ }^{3}$ It impairs quality of life, ${ }^{4}$ results in earlier institutionalisation $^{5}$ and increases healthcare usage, with healthcare-associated costs for frail older adults multiple times that of the non-frail. ${ }^{67}$

For these reasons, the prevention or reversal of frailty has the potential to significantly benefit older adults and society as a whole. As a result, much effort has gone into identifying a cost-effective means of countering frailty, with a growing consensus emerging. A recent systematic review concluded that the combination of resistance exercise and protein supplementation is 'the most effective and easiest to implement intervention to delay or reverse frailty'. ${ }^{8}$ In the majority of studies included, the exercise component was delivered as 
part of a multicomponent exercise programme, that is, including aerobic, balance and flexibility training, in the form of a group class. ${ }^{9-11}$ This concurs with the findings of another systematic review, ${ }^{12}$ which found group interventions to be more effective than those performed individually, as well as providing better value for money, particularly for very frail older adults. There is also strong evidence that such interventions are most effective when combined with a nutritional intervention, with a focus on protein supplementation. ${ }^{13} 14$

This growing evidence base has resulted in incorporation of recommendations for strength training into physical activity guidelines for older adults by a number of public health bodies, including the recently revised UK government physical activity guidelines. ${ }^{15}$ This has been complemented by international guidelines advocating a higher target protein intake of at least $1.2 \mathrm{~g} / \mathrm{kg}$ bodyweight/day for older adults engaged in regular exercise. ${ }^{16}$ Unfortunately, despite these recommendations, uptake of exercise programmes ${ }^{17}$ and levels of dietary proteinintake $^{18}$ among community-dwelling frail older adults remains poor. Despite a willingness among older adults to engage in regular exercise, ${ }^{19}$ one of the main barriers reported is a lack of 'age appropriate programmes'. ${ }^{20}$

To better understand this issue, exercise interventions reported in the literature were analysed using the Frequency, Intensity, Time, Type, Volume, Progression (FITT-VP) framework of the American College of Sports Medicine Guidelines for Exercise Testing and Prescription. $^{21}$ This process revealed some important barriers to translating the evidence base for resistance exercise and protein into practice. Unfortunately, many studies provide incomplete information on the exact nature of their programmes, while others are impractically timeconsuming, labour-intensive or costly to implement on a wider scale (table 1). In order to bridge the gap between research and clinical practice, it became clear that it would be necessary to design and implement a novel intervention, suitable for the majority of frail older adults and deliverable in a community setting.

The aims of this research project are translational in nature. We aimed to address this important gap by designing a novel programme, combining exercise and protein supplementation, that can be easily replicated in a non-clinical setting by non-medical professionals. We now plan to deliver this intervention in a community setting and to evaluate its ability to reverse frailty and improves other related measures in frail older adults.

\section{METHODS AND ANALYSIS}

\section{Intervention development}

Modified Delphi process

Given the multidisciplinary expertise required to develop a novel intervention to reverse frailty, a modified Delphi process was felt to be a suitable approach (figure 1). This is 'a well-recognised consensus method used to determine the extent of agreement on an issue'. ${ }^{22}$ The aim was

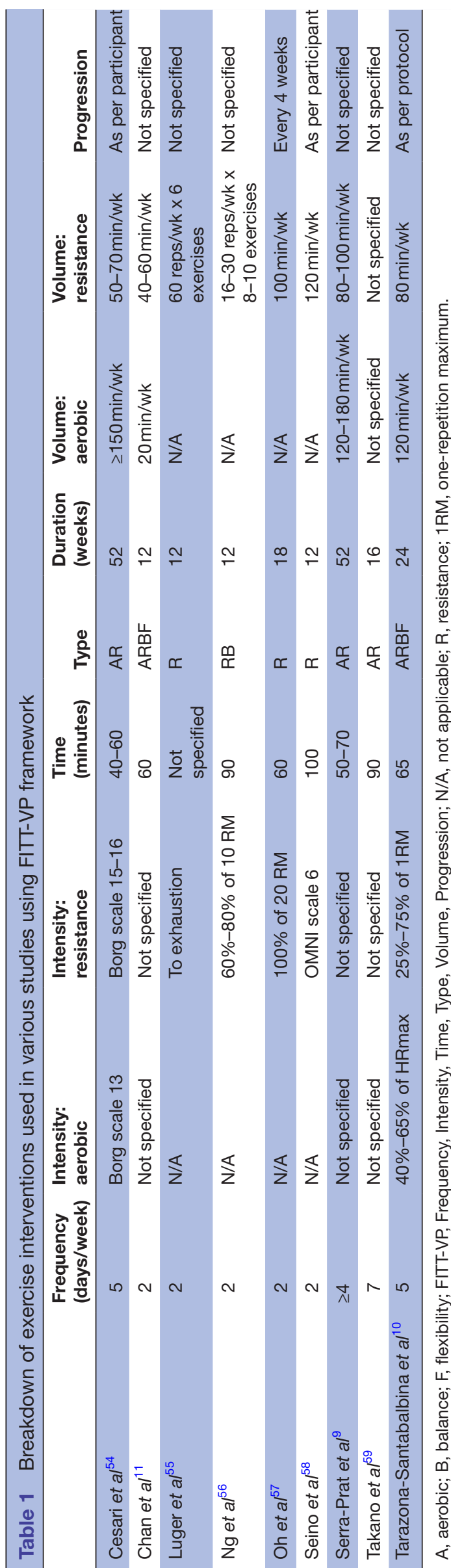




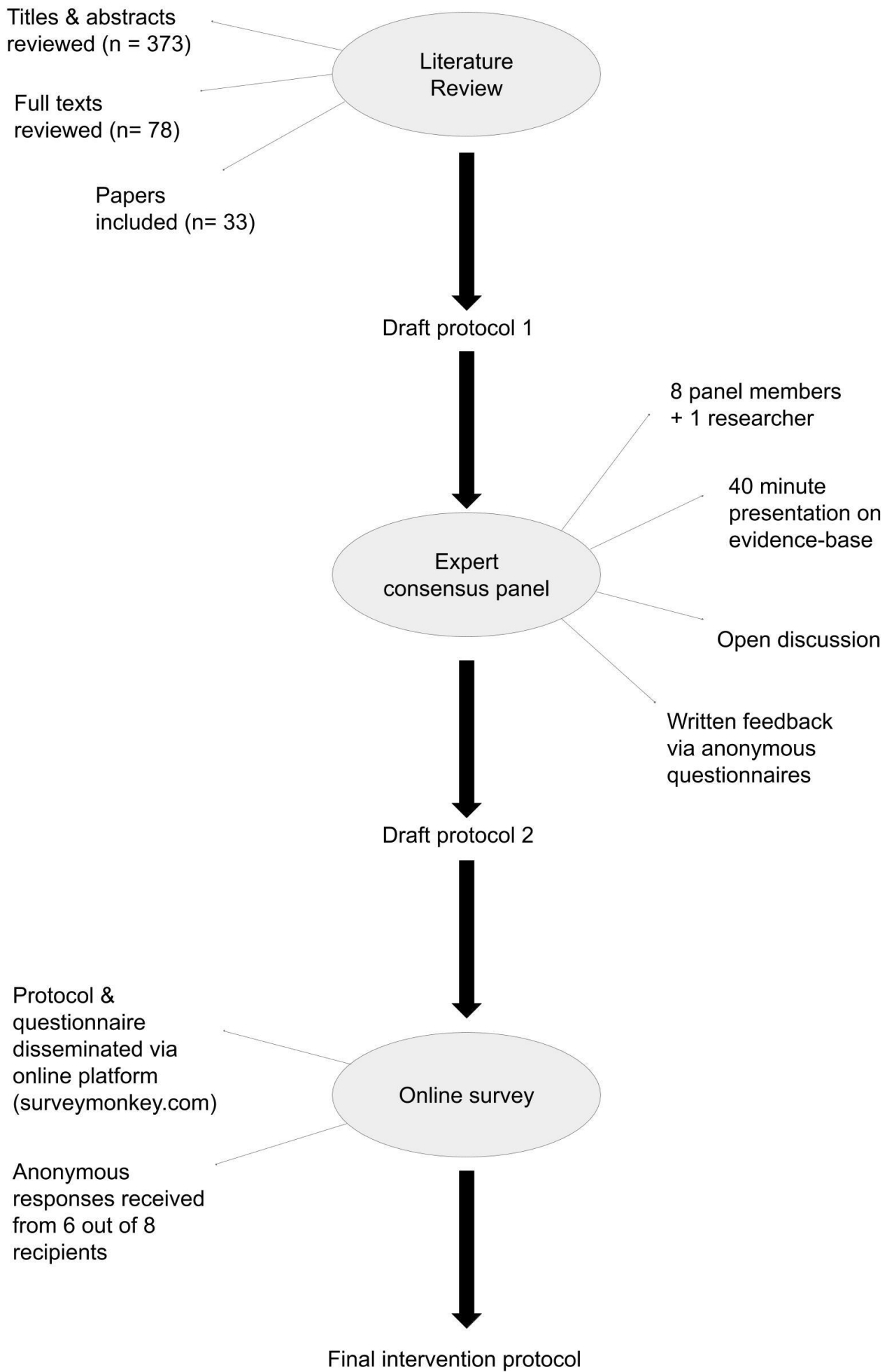

Figure 1 Stages of modified Delphi process.

to design a programme of exercise and protein supplementation by expert consensus that would be (1) acceptable to individuals across a range of degrees of frailty, (2) deliverable by non-specialists in a non-clinical setting as a group class and (3) effective at reversing frailty. This approach allowed us to combine the available evidencebase with clinical experience from a range of relevant disciplines, including Geriatric Medicine, Sport and
Exercise Science, General Practice, Sports Medicine, Geriatric Nursing, Physiotherapy and Nutrition and Dietetics (see acknowledgements for details).

During the introductory meeting, the current evidence base was presented to attendees, along with an initial draft exercise programme, to provide a basis for discussion. Areas where a lack of clear evidence existed were highlighted and discussed. Time was given to open debate 
regarding any other elements that attendees felt required further discussion. An anonymous questionnaire, using a range of question formats to explore these issues, was distributed to all attendees. Following this meeting, the results of the standardised anonymous feedback and group discussion were used to modify the initial draft programme. This revised draft was distributed electronically to all panel members, with an online survey (www. surveymonkey.com) used to receive further anonymous feedback. Examples of programme elements that were decided by consensus at this stage were: a class duration of $60 \mathrm{~min}$; three classes per week; an 8-week programme duration; a focus on resistance over aerobic/balance exercises; $10-12$ participants and two instructors per class.

Additionally, there was consensus that the exercise programme should be supplemented by additional dietary protein, in-keeping with international guidance that older adults engaged in exercise or otherwise physically active should aim for a higher daily protein intake $(\geq 1.2 \mathrm{~g} / \mathrm{kg}$ body weight/day).$^{16} \mathrm{~A}$ decision was taken to opt for a commercially available milk-based supplement. To decide on the preferred preparation, an informal taste test was conducted among attendees to one of the Geriatric Medicine clinics of a large regional teaching hospital $(n=11)$. This included three flavours of protein-supplemented milk and four varieties of a flavoured milk preparation (without protein supplementation). The outcome was one of broad satisfaction with each preparation (protein supplemented milk/flavoured milk), with a range of preference of flavours within each product group. As a result, protein milk was chosen as the most appropriate product, to be consumed as two doses of $250 \mathrm{~mL}$ two times per day. The first portion is to be consumed with breakfast and the second immediately after the exercise class (on 'training' days) or with lunch (on 'non-training' days).

This approach was based on a number of factors. This preparation was felt to represent the optimal balance between protein content, palatability, availability and cost. The dosing regimen is based on the evidence that distributing protein supplementation across the two typically protein-inadequate meals of the day, namely breakfast and lunch, may achieve greater overall stimulation of muscle protein synthesis. ${ }^{23}$ Additionally, consuming the second dose immediately after the classes on 'training days' is predicated on evidence of increased benefit with protein intake in the postexercise period in older adults. ${ }^{24}{ }^{25}$ The $250 \mathrm{~mL}$ dose would provide an additional $12.5-14 \mathrm{~g}$ of additional protein (depending on flavour), in a similar range to the $20 \mathrm{~g}$ supplement advised by one paper. ${ }^{24}$ A nutritional breakdown of the plain flavoured protein milk is provided in table 2.

\section{Pilot}

Following the above steps, the final stage in the development of the intervention was a 4-week pilot, using potential recruits who were found to be insufficiently frail for inclusion in the main study. Examples of changes to the programme that were incorporated as a result of feedback
Table 2 Nutritional information for Avonmore protein milk (plain flavour)

\begin{tabular}{lll}
\hline & Per $100 \mathrm{~mL}$ & Per $500 \mathrm{~mL}$ (daily dose) \\
\hline Energy & $206 \mathrm{~kJ} / 49 \mathrm{kcal}$ & $1030 \mathrm{~kJ} / 245 \mathrm{kcal}$ \\
\hline Fat & $1.0 \mathrm{~g}$ & $5 \mathrm{~g}$ \\
Of which saturates & $0.6 \mathrm{~g}$ & $3 \mathrm{~g}$ \\
Carbohydrate & $4.8 \mathrm{~g}$ & $24 \mathrm{~g}$ \\
Of which sugars & $4.8 \mathrm{~g}$ & $24 \mathrm{~g}$ \\
\hline Protein & $5.1 \mathrm{~g}$ & $25.5 \mathrm{~g}$ \\
Salt & $0.12 \mathrm{~g}$ & $0.60 \mathrm{~g}$ \\
Calcium & $165 \mathrm{mg}$ & $825 \mathrm{mg}$ \\
\hline Magnesium & $28.1 \mathrm{mg}$ & $140.5 \mathrm{mg}$ \\
Zinc & $0.75 \mathrm{mg}$ & $3.75 \mathrm{mg}$ \\
Vitamin $\mathrm{B}_{12}$ & $0.4 \mu \mathrm{g}$ & $20 \mu \mathrm{g}$ \\
Vitamin D & $1 \mu \mathrm{g}$ & $5 \mu \mathrm{g}$ \\
\hline
\end{tabular}

from these individuals included: provision of transport; limitation of equipment to resistance bands and chairs; removal of several exercises that were unsafe or overly challenging; and reduction from four stations to three. This is described in greater detail below in 'patient and public involvement' (PPI).

\section{Study design}

The Diet and Exercise for FRAILty (DEFRAIL) trial will take the form of a non-randomised, single-group, pretest/post-test study, with repeated measures at three time-points over an 18-week period (see figure 2). This trial design was chosen as it was felt to be feasible to deliver, will offer all participants the opportunity to avail of the intervention, and will provide a monitored control period. Participants will undergo a baseline assessment, followed by 8 weeks of regular activity (during which time, participants will be advised to make no change to their diet or usual level of physical activity). After this period, they will be assessed again, before commencing the DEFRAIL intervention (attendance of $>60 \%$ will be required for inclusion in the final analysis). Following completion of this 8-week programme, they will undergo a final assessment (see figure 2 and Standard Protocol Items: Recommendations for Interventional Trials figure). This will allow comparison of changes in outcome measures over the control period with changes over the intervention period. Due to constraints on the numbers of participants per class, the intervention will be conducted multiple times over the course of several months to achieve the desired sample size. Participants will not be monitored beyond the postintervention time point in the current study.

\section{Inclusion and exclusion criteria}

The eligibility criteria are as follows:

$-\geq 65$ of age. 

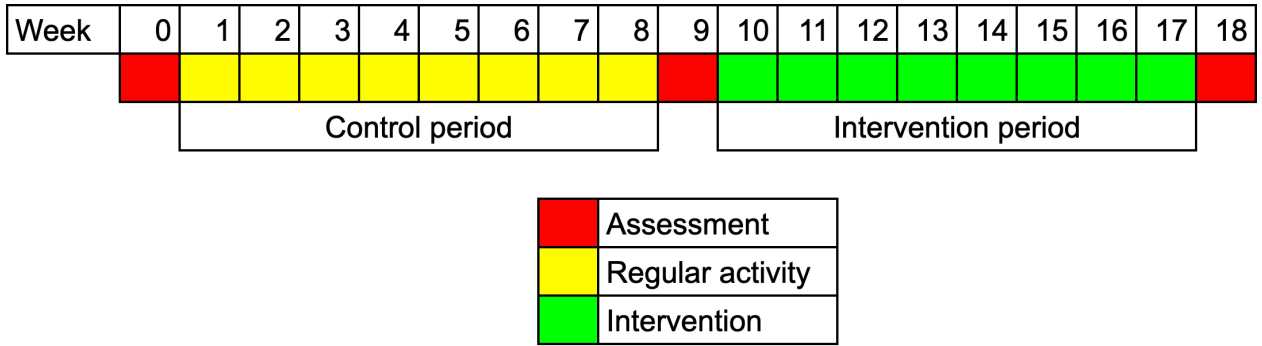

Figure 2 Non-randomised, single-group, pre-test/post-test study design.

- Considered frail by the multidisciplinary team (MDT), that is, a score $\geq 5$ on the Rockwood Clinical Frailty Scale (CFS), ${ }^{26}$ a 9 -point scale ranging from 'very fit' (1) to 'terminally Ill' (9).

- Able to mobilise without assistance (use of a mobility aid is acceptable).

- Not currently participating in any research that could impact on the outcome of this study.

\section{Recruitment}

Sample size

Allowing for a $15 \%$ loss to follow-up and 5\% mortality over the course of the intervention, this study aims to recruit a total of 24 participants. Each participant will provide control and intervention data, to achieve a power of $90 \%$ and a level of significance of $5 \%$ (two sided) for detecting a difference of 1 in the mean Fried Frailty criteria, between the intervention and control periods.

\section{Identification}

Convenience sampling of attendees to specialist clinics in the Geriatric Medicine department of a University hospital will be performed, where a Rockwood CFS score is routinely determined by a member of the MDT. Suitable candidates will be contacted no earlier than 24 hours later and, if agreeable, a detailed participant information leaflet will be sent by post to their address (online supplemental file 1). A subsequent follow-up phone call will be made no earlier than 48 hours later, to answer any outstanding queries. If agreeable to participation after this process, an appointment will be arranged for them to attend for initial assessment.

\section{Assessments}

All assessments will be conducted in the Fitness Laboratory of the Waterford Institute of Technology Arena, a sports facility affiliated with a third-level education institution. Written informed consent will be obtained prior to commencement (online supplemental file 2).

\section{Primary outcome measure}

The primary outcome measure will be the Fried frailty criteria, ${ }^{27}$ a cumulative score out of a maximum of five for the presence or absence of the following criteria: weight loss, self-reported exhaustion, reduced physical activity, weakness (reduced hand-grip strength) and slow gait speed. The values used to determine these criteria have been widely modified in the research setting, ${ }^{28}$ so the specific cut-offs to be used in this study are outlined in online supplemental file 3. A score of 3-5 is considered frail, 1-2 prefrail and 0 robust. This was chosen as it is the most widely cited assessment tool for phenotypic frailty ${ }^{29}$ and has been used to assess the effect of health interventions on frail older adults. ${ }^{30}$

\section{Secondary outcome measures}

A range of secondary outcome measures related to frailty have been chosen (see table 3 ). Some are aimed at detecting physical and functional changes, such as assessment of body mass composition using bioelectrical

Table 3 Secondary outcome measures

\section{Physical \\ performance Category}

Timed 'up \& go'

Psychosocial Montreal Cognitive Assessment

\section{Outcome measure}

30 s sit-to-stand

Geriatric Pain CASP-19

Depression Numerical

Scale-Short Rating Scale

Form

\begin{tabular}{|c|c|c|c|c|c|c|}
\hline Clinical & Bioelectrical Impedance An & sis & & Carotid-Fem & al Pulse Wa & Velocity \\
\hline Biochemical & $\begin{array}{l}\text { C reactive } \\
\text { protein }\end{array}$ & Interleukin-8 & Interleukin-10 & $\begin{array}{l}\text { Tumour } \\
\text { necrosis } \\
\text { factor alpha }\end{array}$ & $\begin{array}{l}\text { Interferon } \\
\text { gamma }\end{array}$ & Cystatin C \\
\hline
\end{tabular}

Dietary Three-day food diaries pre-intervention and intra-intervention

CASP-19, Control, Autonomy, Self-realisation and Pleasure - 19 item. 
impedance analysis and physical performance measures like the Timed 'Up \& Go' test ${ }^{31}$ or the 30 s sit-to-stand test. ${ }^{32}$ Others provide a psychosocial perspective of the individual's well-being, assessing cognition (Montreal Cognitive Assessment) ${ }^{33}$, mood (Geriatric Depression Scale-Short Form) ${ }^{34}$, pain (Pain Numerical Rating Scale) ${ }^{35}$ and quality of life (CASP-19 (Control, Autonomy, Selfrealisation and Pleasure - 19 item) scale) ${ }^{36}$ Finally, a selection of biomarkers known to be associated with frailty has been chosen to examine the effect on underlying physiological processes related to the development or potentiation of frailty. Many of these are soluble biomarkers involved in inflammatory pathways $\left(\mathrm{C}\right.$ reactive protein, ${ }^{37}$ interleukin-6 (IL-6), ${ }^{37} 38$ IL-8, ${ }^{38}$ IL-10, ${ }^{39}$ Tumour Necrosis Factor-alpha ${ }^{37}$ and interferon-gamma ${ }^{40}$ but also include a measure of renal function (Cystatin $\mathrm{C}$ ). ${ }^{41}$ For these analyses, non-fasting blood samples will be taken at each assessment visit. An additional clinical measure of arterial stiffness will be carried out, in the form of carotid-femoral pulse wave velocity. ${ }^{42}$

In order to monitor both adherence with the nutritional intervention and its effect on dietary intake, 3-day food diaries will be recorded by participants during the control and intervention periods. A dietitian will confirm accurate documentation of portion sizes, followed by analysis using the Nutritics.com online platform. This will allow assessment of the effect of the nutritional supplementation on the intake of a range of macronutrients and micronutrients.

\section{Intervention}

The main elements of the DEFRAIL intervention are outlined below in figures 3 and 4 , and table 4 . It is composed of an 8-week exercise programme (supervised multicomponent group exercise class) accompanied by a nutritional supplement (protein milk, $250 \mathrm{~mL}$ two times per day). A more detailed description of the intervention can be found in the Participant Logbook (online supplemental file 4). The 8-week duration was chosen as the optimal balance between efficacy, based on previous similar work (ranging from $6^{43}$ to 12 weeks), ${ }^{13}$ and adherence in clinical practice, realistic for future replication outside of the research setting.

Classes of 10-12 participants will be supervised by two instructors, who will provide demonstration of exercises, supervision of technique and observation for safety purposes. During the 4-week pilot, each instructor underwent training to ensure accurate replication of the intervention. Regular reference to the logbook will be encouraged, to ensure adherence to the protocol.

\section{Patient and public involvement}

The involvement of older adults, the cohort for whom the intervention has been developed, was central to this study. Most significantly, a 4-week pilot was undertaken with prefrail participants $(n=7)$. This gave an opportunity for ineligible candidates who had attended for assessment to participate in a truncated programme, the goal of which was to allow meaningful PPI in the development of the final intervention. To achieve this, group discussions were undertaken with participants during and after each class. This provided invaluable feedback on the user experience, along with advice or suggestions for modifications. The input of family members, some of whom attended these sessions, gave additional perspectives. The informal nature of these conversations, conducted in the setting of the classes themselves, were felt to encourage frank and honest responses. To complement this, phone interviews using standardised questionnaires were also carried out with all pilot participants on completion, in order to provide more structured feedback. Topics discussed included tolerability of the intervention, perceived enablers and barriers to participation, and any other issues felt to be of importance to the individual. This feedback led to a number of changes to the final study design, including addition and removal of specific exercises, changes to the timing and structure of classes and arrangements regarding transport for participants. The plan for dissemination of results to participants is to provide a summary of clinically meaningful outcome measures on completion.

\section{RESULTS}

\section{Data management}

Data collection and storage

All data will be collected in paper format using a standardised data collection form and stored in a locked filing cabinet in the office of the primary researcher. The identity and personal information of all participants will remain confidential. Each study participant will be assigned a unique identifier (DF001, DF002, etc), under which all information will be stored, and the masterfile matching these details to their ID number will be stored on an encrypted and password-protected computer.

\section{Statistical analysis}

Paired t-tests and Wilcoxon signed-rank tests will be used to compare the changes over the control and intervention periods, depending on parametric or non-parametric distribution of data, respectively. Statistical analysis will be performed using IBM SPSS V26.

\section{DISCUSSION}

The development of complex health interventions is challenging and many fail to be translated into clinical practice. ${ }^{44}$ Our goal in designing the DEFRAIL intervention was to produce a programme of exercise and protein supplementation that could have the greatest impact on frailty in clinical practice. To achieve this, we felt our intervention should incorporate a number of characteristics: be suitable for a broad range of levels of frailty, in order to be inclusive; be appropriate for group classes in a community setting with limited specialist equipment, to allow community integration; be deliverable by non-medical 


\section{DEFRAIL INTERVENTION}

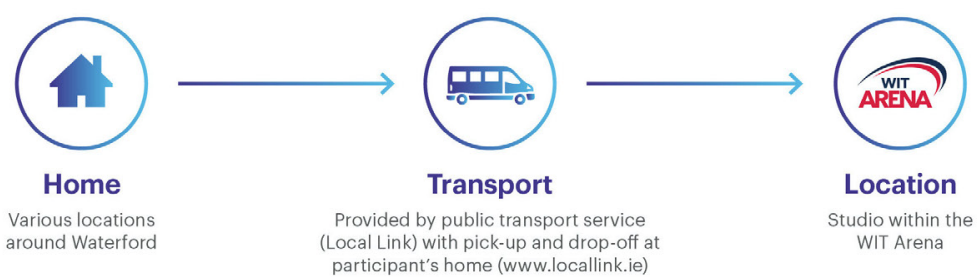

\section{Exercise intervention \\ - Group class \\ - Constant supervision at all times \\ - 2 instructors to 10 participants \\ Two separate groups of 5 with 1 instructor}
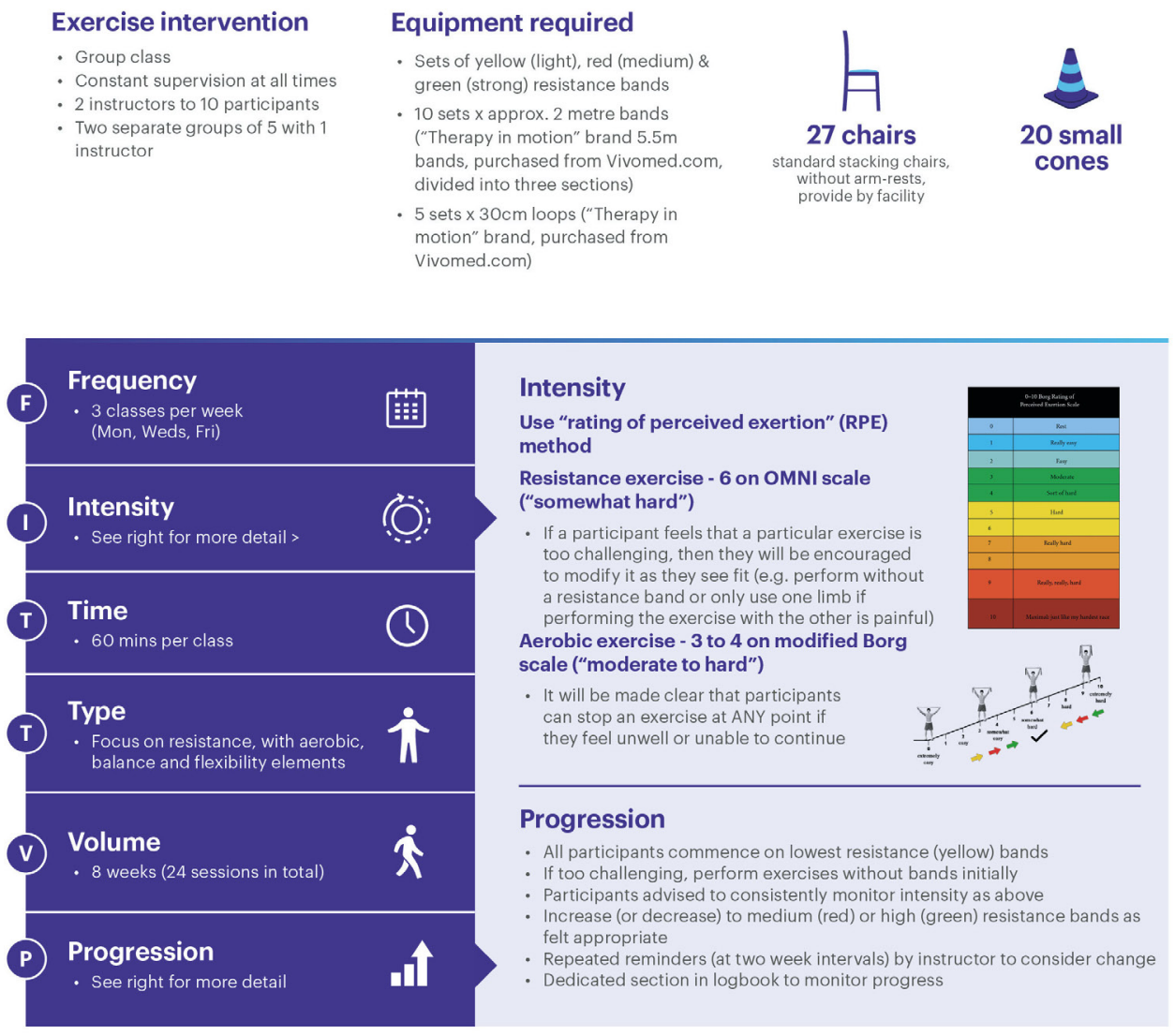

Protein supplementation

Figure 3 DEFRAIL intervention (1 of 2). DEFRAIL, Diet and Exercise for FRAILty; WIT, Waterford Institute of Technology.

professionals with minimal training, to remove the bottleneck presented by limitations in health service capacity; incorporate flexibility, balance and aerobic elements to maximise enjoyment and provide ancillary benefits; be structured to minimise falls risk, in order to allow a feasible instructor:participant ratio while remaining safe; and include an approach to nutritional supplementation that was palatable, affordable and widely available. In order to achieve these aims, a number of compromises were necessary, as discussed below.

We have adopted the "rating of perceived exertion" ${ }^{45}$ approach to the setting of exercise intensity and progression, through the use of the OMNI scale,${ }^{46}$ for resistance, exercises and the Borg CR10 (category-ratio 10) scale ${ }^{47}$ for aerobic exercises. This prioritises participation over rigid prescription, with subsequent individualised progression based on a participant's subjective impression of the difficulty of exercises. In this way, classes following the DEFRAIL protocol are suitable for a broad range of older adults with varying degrees of frailty to participate side by side, in a manner representative of the general older population. We feel this is more appropriate than the use of a "percentage of one-repetition maximum" (\%1RM) approach, that is, the maximum load under which an individual can complete one repetition of a particular exercise. Although still advocated by many for use in older adults, due to concerns that underdosing of exercise prescriptions may occur, ${ }^{48} 49$ in addition to presenting 


\section{Protocol}

BEFRAIL $\begin{array}{ll}\text { (1) Warm-up x } \mathbf{5} \text { mins } & \begin{array}{l}8 \text { exercises performed at an "easy" intensity, progressing from upper } \\ \text { limbs (seated) to lower limbs (seated) to lower limb (standing). }\end{array}\end{array}$ 2 Stretch $\mathbf{5} \mathbf{5}$ mins 12 gentle stretches, performed in sequence from head,
neck, upper limbs, trunk, lower limbs.

\section{Circuits $\times 3 \times 15$ mins each}

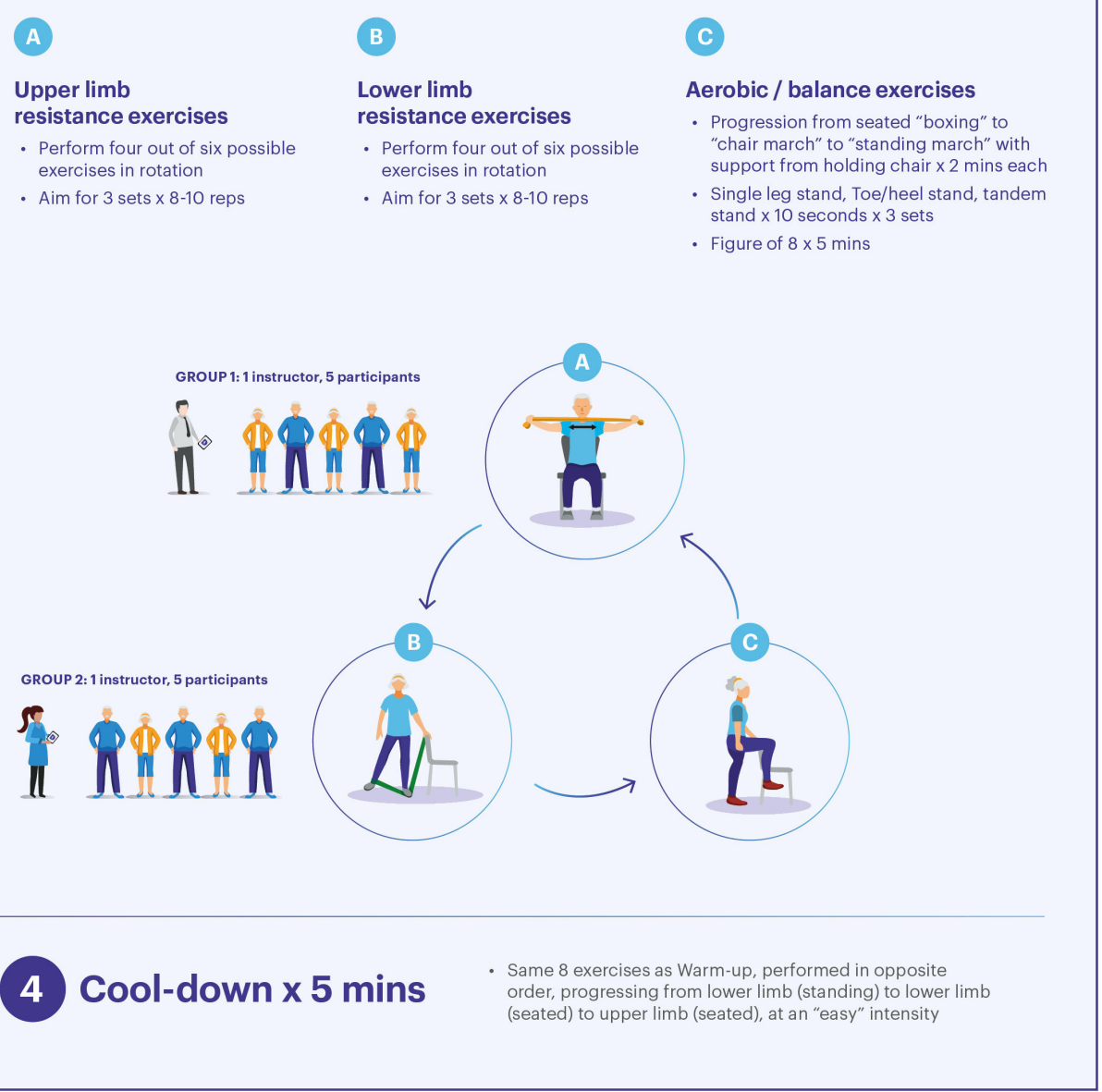

Figure 4 DEFRAIL intervention (2 of 2). DEFRAIL, Diet and Exercise for FRAlLty.

safety concerns, it also represents a barrier to engaging older, particularly frail, adults in strength training. This is because it requires the input of a trained professional at the outset and ongoing supervision over the course of the programme.

The method of nutritional supplementation (proteinsupplemented milk) was also chosen in an attempt to achieve the optimal balance between efficacy and adherence. It is a preparation that it suited to adoption in clinical practice due to its widespread availability, low cost (compared with oral nutritional supplements), familiarity and palatability.

Another major challenge when translating the evidence base into practice is the lack of detail provided by authors when describing their interventions, such that accurate replication is difficult. ${ }^{50}$ To address this, we have provided a clear and comprehensive record of the DEFRAIL intervention in the form of a logbook for instructors and participants (online supplemental file 4). In addition, we have included an itemised breakdown in the form of a 
Table 4 Rotation of resistance exercises

Monday Wednesday Friday

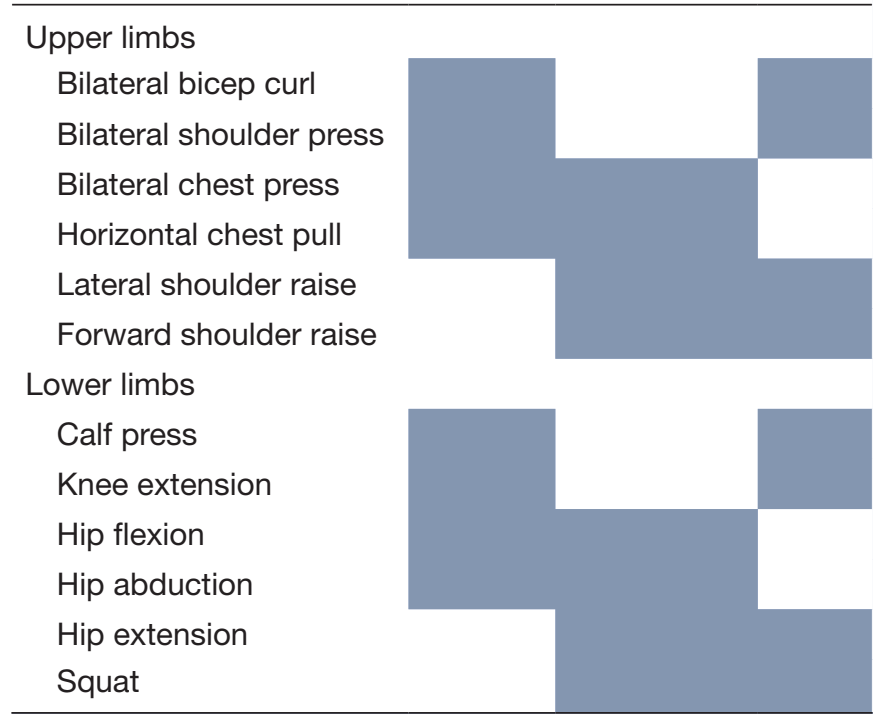

'Template for Intervention Description and Replication' (TIDieR) checklist, which has been shown to improve implementation fidelity in complex community-based interventions. ${ }^{51}$

Due to its widespread use and ease of administration, the Rockwood $\mathrm{CFS}^{52}$ was used as the frailty screening tool in the inclusion criteria, while the Fried frailty criteria, ${ }^{27}$ a more analytical and objective assessment tool, was used as the primary outcome measure. As discussed, the Fried criteria is the most widely cited measure of phenotypic frailty $^{29}$ so has a central place in the discussion around frailty. However, it has a number of recognised limitations for use in this setting, including the heterogeneity of its application due to various modifications. ${ }^{53}$ For this reason, a range of frailty-related secondary outcome measures will also be assessed, as listed above.

The lack of longer-term follow-up of participants is recognised as a limitation of this study but the need to do so in future work is acknowledged, with planned maintenance strategies in place.

Finally, a number of other limitations relate to the study design. These include the lack of randomisation, the single-site nature of this study, and the unblinded nature of the assessments. Additionally, the lack of comparative arms mean that it will not be possible to separate the effects of the various elements of this combined intervention. The resources available to the project and the accessible local frail population did not allow for a fully randomised, multiarm, multisite, blinded study. Following completion of this study, if it is proven to be effective, we would hope to undertake a larger multisite study with blinded assessments. This would involve randomisation of participants into multiple arms, in order to examine the relative contributions of its constituent parts. These include the exercise programme, the nutritional supplementation and the effect of social interaction as part of a community-based group activity.

\section{ETHICS AND DISSEMINATION}

This study received ethical approval from the Research Ethics committees of both the Health Service Executive South-Eastern Area and Waterford Institute of Technology. Its findings will be disseminated through various means, including journal publications, conference presentations and other forms of public engagement.

\section{Reporting of adverse events}

Given the pragmatic nature of the trial and the overarching aim of providing a reproducible intervention, medical oversight will not be provided for the intervention, despite the involvement of physicians in the design and conduct of the study. Instead, all adverse events are to be dealt with initially by the staff of the facility where the classes take place, with further medical review to be arranged as appropriate, via standard community or emergency medical services. However, all adverse events will be reported to the primary researcher and a detailed review of the circumstances will be conducted as necessary.

\section{Status}

This trial commenced on 13 May 2019 and is expected to be complete by December 2020 .

\section{Twitter Pádraig Bambrick @pbambrick}

Acknowledgements The members of the expert consensus panel were Prof. John Cooke, Prof. Ríona Mulcahy, Dr. George Pope (Geriatric Medicine), Dr. Michael Harrison (Sports \& Exercise Science), Dr Noel McCaffrey General Practice, Sports Medicine), Maggie Bolger (Geriatric Nursing), Niamh Phelan (Physiotherapy), Emma Grant (Nutrition \& Dietetics) and the coordinator was Dr. Pádraig Bambrick (Geriatric Medicine). Valuable advice on the approach to nutritional supplementation was provided by Dr. Linda Giblin and Dr. André Brodkorb of the Moorepark Teagasc Food Research Centre, Fermoy, Co. Cork. Statistical support was provided by Dr Fiona Boland of the Data Science Centre at RCSI. The classes will be delivered by four personal trainers, in rotation (two per class) (Anna Hawrylak, Barry 0'Connor, Michelle Mullaly and Anna Flynn). We would like to acknowledge the advisory role of the participants of our pilot trial, all of whom provided constructive feedback on their experiences. This contributed significantly to the final design of the intervention and study. We would like to thank Michelle Collins and Kate Lennon at Glanbia Ireland for their financial and logistical support. This project is being carried out under the Strategic Academic Recruitment MD (StAR MD) programme of RCSI.

Contributors The initial exercise intervention was designed by PB and NP, with revision by an expert consensus group. The assessment protocol was designed and trialled by PB and TB, as part of ongoing collaborative work. Food diary records will be assessed and analysed by EG. This manuscript was written by PB, with supervision, input and feedback at all stages by JC, RM and MH. All authors have read and approved the final manuscript.

Funding This work was supported by the Royal College of Surgeons in Ireland (RCSI) and Glanbia Ireland DAC.

Competing interests The protein-supplemented milk used in this study is a commercial product of one of the main funders, Glanbia Ireland DAC (Avonmore Protein milk).

Patient consent for publication Not required.

Provenance and peer review Not commissioned; externally peer reviewed.

Supplemental material This content has been supplied by the author(s). It has not been vetted by BMJ Publishing Group Limited (BMJ) and may not have been peer-reviewed. Any opinions or recommendations discussed are solely those of the author(s) and are not endorsed by BMJ. BMJ disclaims all liability and 
responsibility arising from any reliance placed on the content. Where the content includes any translated material, BMJ does not warrant the accuracy and reliability of the translations (including but not limited to local regulations, clinical guidelines, terminology, drug names and drug dosages), and is not responsible for any error and/or omissions arising from translation and adaptation or otherwise.

Open access This is an open access article distributed in accordance with the Creative Commons Attribution Non Commercial (CC BY-NC 4.0) license, which permits others to distribute, remix, adapt, build upon this work non-commercially, and license their derivative works on different terms, provided the original work is properly cited, appropriate credit is given, any changes made indicated, and the use is non-commercial. See: http://creativecommons.org/licenses/by-nc/4.0/.

\section{ORCID iD}

Pádraig Bambrick http://orcid.org/0000-0002-7323-708X

\section{REFERENCES}

1 Clegg A, Young J. The frailty syndrome. Clin Med 2011;11:72-5.

2 Kojima G, lliffe S, Walters K. Frailty index as a predictor of mortality: a systematic review and meta-analysis. Age Ageing 2018;47:193-200.

3 Stow D, Matthews FE, Barclay S, et al. Evaluating frailty scores to predict mortality in older adults using data from population based electronic health records: case control study. Age Ageing 2018;47:564-9.

4 Crocker TF, Brown L, Clegg A, et al. Quality of life is substantially worse for community-dwelling older people living with frailty: systematic review and meta-analysis. Qual Life Res 2019;28:2041-56.

5 Roe L, Normand C, Wren M-A, et al. The impact of frailty on healthcare utilisation in Ireland: evidence from the Irish longitudinal study on ageing. BMC Geriatr 2017;17:203.

6 Hajek A, Bock J-O, Saum K-U, et al. Frailty and healthcare costslongitudinal results of a prospective cohort study. Age Ageing 2018;47:233-41.

7 Kojima G. Increased healthcare costs associated with frailty among community-dwelling older people: a systematic review and metaanalysis. Arch Gerontol Geriatr 2019;84:103898.

8 Travers J, Romero-Ortuno R, Bailey J, et al. Delaying and reversing frailty: a systematic review of primary care interventions. $\mathrm{Br} J \mathrm{Gen}$ Pract 2019;69:e61-9.

9 Serra-Prat M, Sist X, Domenich R, et al. Effectiveness of an intervention to prevent frailty in pre-frail community-dwelling older people consulting in primary care: a randomised controlled trial. Age Ageing 2017;46:401-7.

10 Tarazona-Santabalbina FJ, Gómez-Cabrera MC, Pérez-Ros P, et al. A multicomponent exercise intervention that reverses frailty and improves cognition, emotion, and social networking in the community-dwelling frail elderly: a randomized clinical trial. J Am Med Dir Assoc 2016;17:426-33.

11 Chan D-CD, Tsou H-H, Chang C-B, et al. Integrated care for geriatric frailty and sarcopenia: a randomized control trial. $J$ Cachexia Sarcopenia Muscle 2017;8:78-88.

12 Apóstolo J, Cooke R, Bobrowicz-Campos E, et al. Effectiveness of interventions to prevent pre-frailty and frailty progression in older adults: a systematic review. JBI Database System Rev Implement Rep 2018;16:140-232.

13 Kim H, Suzuki T, Kim M, et al. Effects of exercise and milk fat globule membrane (MFGM) supplementation on body composition, physical function, and hematological parameters in community-dwelling frail Japanese women: a randomized double blind, placebo-controlled, follow-up trial. PLoS One 2015;10:e0116256.

14 Hsieh T-J, Su S-C, Chen C-W, et al. Individualized home-based exercise and nutrition interventions improve frailty in older adults: a randomized controlled trial. Int J Behav Nutr Phys Act 2019;16:119.

15 CMO U. UK Chief Medical Officers' Physical Activity Guidelines, 2019.

16 Bauer J, Biolo G, Cederholm T, et al. Evidence-Based recommendations for optimal dietary protein intake in older people: a position paper from the PROT-AGE Study Group. J Am Med Dir Assoc 2013;14:542-59.

17 Sun F, Norman IJ, While AE. Physical activity in older people: a systematic review. BMC Public Health 2013;13:449.

18 Coelho-Júnior HJ, Calvani R, Picca A, et al. Protein-Related dietary parameters and frailty status in older Community-Dwellers across different frailty instruments. Nutrients 2020;12:508.

19 Mehra S, Dadema T, Kröse BJA, et al. Attitudes of older adults in a group-based exercise program toward a blended intervention; a Focus-Group study. Front Psychol 2016;7:1827.
20 Burton E, Farrier K, Lewin G, et al. Motivators and barriers for older people participating in resistance training: a systematic review. $J$ Aging Phys Act 2017;25:311-24.

21 Medicine ACoS. ACSM's guidelines for exercise testing and prescription. 10 ed. Philadelphia: Lippincott Williams \& Wilkins, 2018.

22 Roller-Wirnsberger R, Masud T, Vassallo M, et al. European postgraduate curriculum in geriatric medicine developed using an international modified Delphi technique. Age Ageing 2019;48:291-9.

23 Mamerow MM, Mettler JA, English KL, et al. Dietary protein distribution positively influences $24-\mathrm{h}$ muscle protein synthesis in healthy adults. $J$ Nutr 2014;144:876-80.

24 Esmarck B, Andersen JL, Olsen S, et al. Timing of postexercise protein intake is important for muscle hypertrophy with resistance training in elderly humans. J Physiol 2001;535:301-11.

25 Candow DG, Chilibeck PD. Timing of creatine or protein supplementation and resistance training in the elderly. Appl Physiol Nutr Metab 2008;33:184-90.

26 Rockwood K, Song X, MacKnight C, et al. A global clinical measure of fitness and frailty in elderly people. CMAJ 2005;173:489-95.

27 Fried LP, Tangen CM, Walston J, et al. Frailty in older adults: evidence for a phenotype. J Gerontol A Biol Sci Med Sci 2001;56:M146-57.

28 Theou O, Cann L, Blodgett J, et al. Modifications to the frailty phenotype criteria: systematic review of the current literature and investigation of 262 frailty phenotypes in the survey of health, ageing and retirement in Europe. Ageing Res Rev 2015;21:78-94.

29 Buta BJ, Walston JD, Godino JG, et al. Frailty assessment instruments: systematic characterization of the uses and contexts of highly-cited instruments. Ageing Res Rev 2016;26:53-61.

30 Frost R, Belk C, Jovicic A, et al. Health promotion interventions for community-dwelling older people with mild or pre-frailty: a systematic review and meta-analysis. BMC Geriatr 2017;17:157.

31 Podsiadlo D, Richardson S. The timed "Up \& Go": a test of basic functional mobility for frail elderly persons. J Am Geriatr Soc 1991;39:142-8

32 Bohannon RW. Five-repetition sit-to-stand test: usefulness for older patients in a home-care setting. Percept Mot Skills 2011;112:803-6.

33 Nasreddine ZS, Phillips NA, Bédirian V, et al. The Montreal cognitive assessment, MoCA: a brief screening tool for mild cognitive impairment. J Am Geriatr Soc 2005;53:695-9.

34 Sheikh JI YJ. Geriatric depression scale (GDS): recent evidence anddevelopment of a shorter version. Clinical Gerontology 1986;5:165-73. doi:10.1300/J018v05n01_09

35 Turk DC, Rudy TE, Sorkin BA. Neglected topics in chronic pain treatment outcome studies: determination of success. Pain 1993;53:3-16.

36 Hyde M, Wiggins RD, Higgs $\mathrm{P}$, et al. A measure of quality of life in early old age: the theory, development and properties of a needs satisfaction model (CASP-19). Aging Ment Health 2003;7:186-94.

37 Marcos-Pérez D, Sánchez-Flores M, Maseda A, et al. Frailty in older adults is associated with plasma concentrations of inflammatory mediators but not with lymphocyte subpopulations. Front Immunol 2018;9:1056.

38 Hsu B, Hirani V, Cumming RG, et al. Cross-Sectional and longitudinal relationships between inflammatory biomarkers and frailty in community-dwelling older men: the Concord health and ageing in men project. J Gerontol A Biol Sci Med Sci 2019;74:835-41.

39 Jankord R, Jemiolo B. Influence of physical activity on serum IL-6 and IL-10 levels in healthy older men. Med Sci Sports Exerc 2004;36:960-4.

40 Mohamad M, Ebeid S, Shawky Khater M, et al. Interferon- gammainducible guanosine triphosphate cyclohydrolase 1 (GTP-CH1) pathway is associated with frailty in Egyptian elderly. Rep Biochem Mol Biol 2018;7:52-8.

41 Hart A, Blackwell TL, Paudel ML, et al. Cystatin C and the risk of frailty and mortality in older men. J Gerontol A Biol Sci Med Sci 2017;72:965-70.

42 Orkaby AR, Lunetta KL, Sun FJ, et al. Cross-Sectional association of frailty and arterial stiffness in community-dwelling older adults: the Framingham heart study. J Gerontol A Biol Sci Med Sci 2019;74:373-9.

43 Losa-Reyna J, Baltasar-Fernandez I, Alcazar J, et al. Effect of a short multicomponent exercise intervention focused on muscle power in frail and pre frail elderly: a pilot trial. Exp Gerontol 2019;115:114-21.

44 Contopoulos-loannidis DG, Alexiou GA, Gouvias TC, et al. Medicine. life cycle of translational research for medical interventions. Science 2008;321:1298-9.

45 Borg GA. Psychophysical bases of perceived exertion. Med Sci Sports Exerc 1982;14:377???381-81. 
46 Buskard ANL, Jacobs KA, Eltoukhy MM, et al. Optimal approach to load progressions during strength training in older adults. Med Sci Sports Exerc 2019;51:2224-33.

47 Borg GA. Borg's Perceived Exertion and Pain Scales. Champaign, IL: Human Kinetics, 1998.

48 Fragala MS, Cadore EL, Dorgo S, et al. Resistance training for older adults: position statement from the National strength and conditioning association. J Strength Cond Res 2019;33:2019-52.

49 van Dongen EJI, Haveman-Nies A, Wezenbeek NLW, et al. Effect, process, and economic evaluation of a combined resistance exercise and diet intervention (ProMuscle in practice) for community-dwelling older adults: design and methods of a randomised controlled trial. BMC Public Health 2018;18:877.

50 Hoffmann TC, Glasziou PP, Boutron I, et al. Better reporting of interventions: template for intervention description and replication (TIDieR) checklist and guide. BMJ 2014;348:g1687.

51 Bird M-L, Mortenson WB, Eng JJ. Evaluation and facilitation of intervention fidelity in community exercise programs through an adaptation of the TIDier framework. BMC Health Serv Res 2020;20:68.

52 Mitnitski AB, Mogilner AJ, Rockwood K. Accumulation of deficits as a proxy measure of aging. ScientificWorldJournal 2001;1:323-36.

53 Faller JW, Pereira DdoN, de Souza S, et al. Instruments for the detection of frailty syndrome in older adults: a systematic review. PLoS One 2019;14:e0216166.
54 Cesari M, Vellas B, Hsu F-C, et al. A physical activity intervention to treat the frailty syndrome in older persons-results from the LIFE-P study. J Gerontol A Biol Sci Med Sci 2015;70:216-22.

55 Luger E, Dorner TE, Haider S, et al. Effects of a home-based and Volunteer-Administered physical training, nutritional, and social support program on malnutrition and frailty in older persons: a randomized controlled trial. J Am Med Dir Assoc 2016;17:671. e9-671.e16.

$56 \mathrm{Ng}$ TP, Feng L, Nyunt MSZ, et al. Nutritional, physical, cognitive, and combination interventions and frailty reversal among older adults: a randomized controlled trial. Am J Med 2015;128:1225-36.

57 Oh S-L, Kim H-J, Woo S, et al. Effects of an integrated health education and elastic band resistance training program on physical function and muscle strength in community-dwelling elderly women: Healthy Aging and Happy Aging II study. Geriatr Gerontol Int 2017;17:825-33.

58 Seino S, Nishi M, Murayama $\mathrm{H}$, et al. Effects of a multifactorial intervention comprising resistance exercise, nutritional and psychosocial programs on frailty and functional health in communitydwelling older adults: a randomized, controlled, cross-over trial. Geriatr Gerontol Int 2017;17:2034-45.

59 Takano E, Teranishi T, Watanabe T, et al. Differences in the effect of exercise interventions between prefrail older adults and older adults without frailty: a pilot study. Geriatr Gerontol Int 2017;17:1265-9. 